\title{
Achieving superlubricity in DLC films by controlling bulk, surface, and tribochemistry
}

\author{
Ali ERDEMIR*, Osman ERYILMAZ \\ Energy Systems Division, Argonne National Laboratory, 9700 S. Cass Avenue, Argonne, IL 60439, USA \\ Received: 06 June 2014 / Accepted: 08 June 2014 \\ (C) The author(s) 2014. This article is published with open access at Springerlink.com
}

\begin{abstract}
Superlubricity refers to a sliding regime in which contacting surfaces move over one another without generating much adhesion or friction [1]. From a practical application point of view, this will be the most ideal tribological situation for many moving mechanical systems mainly because friction consumes large amounts of energy and causes greenhouse gas emissions [2]. Superlubric sliding can also improve performance and durability of these systems. In this paper, we attempt to provide an overview of how controlled or targeted bulk, surface, or tribochemistry can lead to superlubricity in diamond-like carbon (DLC) films. Specifically, we show that how providing hydrogen into bulk and near surface regions as well as to sliding contact interfaces of DLC films can lead to super-low friction and wear. Incorporation of hydrogen into bulk DLC or near surface regions can be done during deposition or through hydrogen plasma treatment after the deposition. Hydrogen can also be fed into the sliding contact interfaces of DLCs during tribological testing to reduce friction. Due to favorable tribochemical interactions, these interfaces become very rich in hydrogen and thus provide super-low friction after a brief run-in period. Regardless of the method used, when sliding surfaces of DLC films are enriched in hydrogen, they then provide some of the lowest friction coefficients (i.e., down to 0.001). Time-of-flight secondary ion mass spectrometer (TOF-SIMS) is used to gather evidence on the extent and nature of tribochemical interactions with hydrogen. Based on the tribological and surface analytical findings, we provide a mechanistic model for the critical role of hydrogen on superlubricity of DLC films.
\end{abstract}

Keywords: Superlubricity; diamond-like carbon; TOF-SIMS; test environment; lubrication mechanisms

\section{Introduction}

Energy and material losses due to friction and wear in moving mechanical systems account for huge economic and environmental burdens on all nations. For example, according to US Energy Information Agency, total $\mathrm{CO}_{2}$ emissions due to gasoline and diesel fuel consumption by transportation sector in the United States was about 1,089 and 422 million metric tons in 2012, respectively, and this accounted for $29 \%$ of total U.S. energy-related $\mathrm{CO}_{2}$ emissions. Significant amount of fuels is spent to overcome friction in moving mechanical parts in engines. For passenger

\footnotetext{
* Corresponding author: Ali ERDEMIR.

E-mail: erdemir@anl.gov
}

cars alone, we waste about 350 million tons of petroleum per year to overcome friction globally [2]. Not to mention, $\mathrm{CO}_{2}$ emission resulting from fuels spent to overcome friction in all motored vehicles is also enormous and currently estimated to be more than 6 billion tons per year. When energy losses and emission figures due to remanufacturing and replacement of worn parts are also considered, the energy and environmental impacts of transportation related activities will become even much greater. Overall, the economic losses resulting from friction and wear in transportation are already huge, and with rapidly growing road transportation and other industrial activities, there is no doubt that the situation will become much more exorbitant in the near future than before.

Starting from the very early ages, mankind has 
appreciated the significance of friction in his daily life, and with increased social, agricultural, and military activities during the last millennium, this awareness has grown further, and nowadays the friction has become one of the most important physical phenomena affecting our mobility and all kinds of industrial activities. Thanks to the concerted efforts of many dedicated scientists and engineers, significant strides have been made over the past century in not only better understanding but also controlling friction from atomic-to-engineering-scales. As a result of these developments, governing laws and principles of friction have been put on a solid foundation, and at the same time, a myriad of new low friction materials, coatings, and lubricants have been discovered and put in practice to minimize the adverse impacts of friction on all moving mechanical systems. Despite all these positive developments, we still waste huge amounts of energy to friction in transportation, manufacturing, and other industrial fields. Accordingly, with increasing worldwide concerns over energy security, environmental sustainability, and economic viability, research on low-friction materials, coatings, and lubricants has recently been intensified, and as a results of these, numerous new materials and lubricants have been developed. In fact, most companies involved in lubrication and manufacturing of motored vehicles are now pursuing research to further reduce friction and thus improve fuel economy and durability of their vehicles.

Among the many friction control technologies, advanced tribological coatings have made significant positive impacts on a variety of manufacturing and transportation systems [3, 4]. Most of the machining and manufacturing tools are now coated with hard physical vapor deposition (PVD) and chemical vapor deposition (CVD) coatings to combat friction and wear [4]. Those engine components that are subject to sever operating conditions are also coated by a variety of hard and lubricious coatings [5]. Among others, diamond-like carbon (DLC) coatings (developed more than half a century ago [6]) have gained an overwhelming attention in recent years due to their unusual friction and wear properties [7]. They are applied on rolling, rotating and sliding components of many types of machines to control friction and wear and hence help reduce fuel consumption and
$\mathrm{CO}_{2}$ emissions. Overall, the current industrial trend is toward much increased uses of such coatings (as their price comes down and quality increases) to more effectively control friction and wear in all types of moving mechanical systems to meet the harsher operational conditions of modern machines.

As mentioned above, DLC films have been discovered more than half a century ago [6], but their large-scale industrial uses have not started until late 1980s. Some of the very first applications were in the hard-disk industry where such coatings with ever diminishing thickness (which is now down to 1-2 nm) have served well in increasing areal data storage densities of such disk drives to nearly $1 \mathrm{~TB} / \mathrm{in}^{2}$ today. These coatings are also used in numerous consumer goods such as wrist watches, razor blades, even inside of beer cans to improve storage life and taste, etc. [8]. However, their biggest current applications are in the automotive fields as they are now routinely used in fuel injectors, tappets, piston pins and rings, gears, bearings, etc. [7, 9-11]. Some of the DLC coatings are able to afford friction coefficients of down to 0.01 under oil lubricated sliding conditions $[9,10]$. Overall, during the last two decades or so, the interest in these films exploded and there are now several coating companies and their affiliates providing high-quality DLC coatings to many end-users in the automotive and other industrial fields. Figure 1 shows some of the critical engine components that are coated with DLC films for friction and wear control in engines.

DLC coatings can be doped or alloyed with some elements to increase their functionality beyond what is feasible with pure or monolithic forms [12]. In some cases, the structural architecture may consist of nano-scale multi-layers or nano-crystalline grains which help increase toughness and other properties (such as superior hardness, higher thermal stability, electrical conductivity, lower internal stresses, etc.).

At present, most DLC films are deposited using a PVD or CVD system. The carbon source or precursor

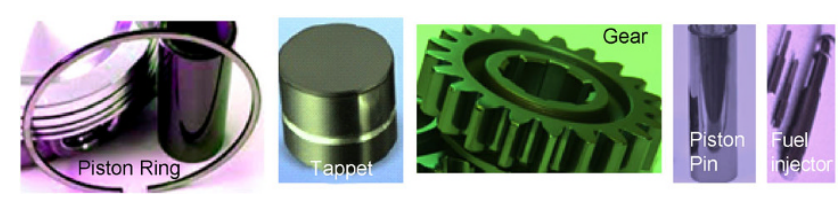

Fig. 1 Examples of engine components coated with DLC. 
materials used during deposition can vary from solid carbon or graphite targets to gaseous and liquid hydrocarbons. Those DLCs derived from solid carbon targets are often hydrogen free and they can be super-hard (especially if deposited by an arc-PVD or pulse laser deposition (PLD) process), however, their frictional properties may not be very good if the test environment is inert or does not contain humidity or hydrogen. Plasma enhanced CVD is a very common method to deposit hydrogenated-DLCs. Typically, a hydrocarbon gas (such as acetylene, methane, etc.) is used as the carbon source in this method and the resultant DLCs may also consist of large amounts of hydrogen in their structures. Structurally, DLC coatings are amorphous and the carbon atoms in their random network structure are bonded to one another by strong $\mathrm{sp}^{2}$ and $\mathrm{sp}^{3}$ type bonds [13]. Their frictional properties are exceptional in inert and dry environments but somewhat inferior when there is high humidity or oxygen in the test chamber.

High proportion of $\mathrm{sp}^{3}$-bonding in a non-hydrogenated DLC (achievable by arc-PVD or PLD methods) is analogous with super-hardness and high resistance to wear and thermal degradations. These DLCs are known as tetragonal amorphous carbon, or ta-C which are widely used in various engine applications where in addition to high hardness and wear resistance, thermal stability is also important [9]. High internal stress build-up during deposition limits the thickness of ta-C coatings to a few micrometers and when deposited by arc-PVD, high surface roughness due to micro-droplets poses some problems in tribological applications. Filtered arc-PVD eliminates these problems but reduces the deposition rates. Those DLCs extracted from hydrocarbon gases contain large amounts of bonded and free hydrogen in them and their mechanical (i.e., hardness) and tribological properties tend to be very different from those of the ta-C type DLCs. Overall, there exist so many DLCs nowadays with very different structures and chemistries and as a results different friction and wear properties. Colorwise or visually, it is very difficult to distinguish one DLC from another but when tested for their tribological performance, they differ substantially especially under dry sliding conditions.

Overall, great strides have been made in the design, deposition and diverse utilization of DLC coatings.
Many dedicated studies has confirmed that under the right tribological or environmental conditions, both hydrogenated and hydrogen-free DLCs can exhibit super-low friction (i.e., below 0.01 threshold) and wear properties. In the case of highly-hydrogenated DLCs, it was shown that even down to 0.001 friction coefficients are feasible in controlled test environments [14]. In the following sections, a short overview of superlubricity in carbon-based materials is provided first and then the recent discoveries and other developments that enabled superlubricity in DLC films are discussed next. In particular, the importance of the chemical composition of the bulk and nearsurface regions is highlighted and the impact of tribochemical interactions on superlubric behavior is also emphasized.

\section{Superlubricity in carbon-based nano- materials and coatings}

It is very important to remind that many of the finest tribological materials and lubricants that are in use today are either made of carbon or consist of carbon. For example, the bulk of current liquid lubricants is nothing but made out of long-chain hydrocarbon molecules. Graphite is another carbon-based material known for its great solid lubrication properties. Diamond is a solid carbon form with extreme hardness and low-friction. Another great solid lubricant is Teflon (or PTFE) whose backbone is nothing but made of carbon. Some of the emerging 1, 2, and 3D nanomaterials (graphene, buckyball, nano-diamond, nano-onion, and nano-tubes and -fibers) are all carbonbased and have shown great promise for a variety of tribological applications in recent laboratory tests [14-27]. There also exist several other carbon-based materials, such as transition metal carbides, boron carbide, carbon-carbon composites, bulk glassy carbons, and carbon-blacks which are used for a variety of tribological purposes (including fillers for brakes and tires). Overall, our life would have been very difficult if not impossible without carbon both biologically and tribologically.

Fundamental tribological research into various 1, 2, and 3D carbon-based materials has confirmed the existence of superlubric sliding capabilities in many 
of them. In particular, the nano-to-micro-scale superlubricity of 2D graphite and graphene, 3D diamond, and 1D carbon nanotubes has well been documented in Refs. [15-26]. In most of these materials, superlubricity was either attributed to an incommensurability phenomenon $[19,24,26]$ or surface chemical effects which can create a highly passive and hence nonreactive contact interface which suppresses stiction and hence friction [3,28-32]. Incommensurability relates to avoidance of one-to-one correspondence or registry between surface atoms at contact interfaces. With the use of atomic force microscopy/friction force microscopy (AFM/FFM) type nanotribology test machines, it was shown that when the incommensurability requirement is met, the friction coefficient of graphite sheets can reach values down to zero [19]. Specifically, when graphite sheets were rotated out of registry (or brought into a total incommensurate state), a smooth transition from high degree of stick-slip behavior to smooth sliding with little or no frictional force was generated.

In other studies involving graphite, alternating monolayers of $\mathrm{C}_{60}$ were inserted between the sheets of graphite to achieve superlubricity [20]. It was shown that with such $\mathrm{C}_{60}$ intercalation, the inter-planar spacing between graphite sheets is increased significantly, and during relative motion, these widely spaced sheets together with $\mathrm{C}_{60}$ acting as molecular-scale ball bearings lowered friction down to zero level. In a recent study focused on graphite flakes, Liu et al. have demonstrated microscale superlubricity between lithographically prepared free-standing graphite mesa and original graphite surface [21]. Specifically, they showed that when the mesa is moved from its original position with a micromanipulator, this sheared section retracts back to its original place without creating any friction.

In recent tribological studies dealing with graphene (a 2D carbon structure), researchers have shown that both superlow wear and friction are feasible under the right kinds of environmental and/or test conditions. Specifically, Berman et al. have shown that spreading few-layers of graphene on a sliding surface can lower friction by factors of 5 to 6 , while wear by factors of 4 orders of magnitude [22, 23]. In other studies, superlubricity was achieve with graphene during nanoscale friction and wear tests [24]. Specifically, it was shown that friction force goes down to nearly zero level when the number of graphene layers at sliding interface is decreased from several to a few (2 or 3) layers. Feng et al. also have shown that small graphene nanoflakes can move or slide over freely on larger graphene sheets when the incommensurability conditions are met at very low temperatures [25].

Superlubric sliding behavior was also reported for double-walled carbon nanotubes (DWCNT). Specifically, Zhang et al. demonstrated that inner shell of a centimeter-long DWCNT can be pulled out of the outer shell effortlessly (creating a friction force of less than $1 \mathrm{nN}$ ) regardless of the length of the nanotube thus confirming the existence of macroscale superlubricity in such carbon material [26]. Overall, carbonbased materials offered unique opportunities for scientists and engineers to achieve and understand superlubricity over a very broad range of scales and test conditions.

Diamond is the hardest known material and has been the subject of many dedicated tribological studies for its friction and wear behavior under a wide range of test conditions in the past. Thin film version of diamond has been around for quite a long time and produced by a number of CVD methods. In our laboratory, we have been working in the diamond synthesis field since early 1990s. Specifically, we have been producing, characterizing and testing macro, nano, and ultra-nano crystalline diamond films for a variety of engineering applications [27,33]. Among others, ultra-nano crystalline diamond films provided the best overall friction and wear performance to sliding contact surfaces of a variety of mechanical, tribological, and micro-electromechanical devices $[34,35]$.

Hypothetically, the low-friction nature of diamond is associated with a highly passive surface (especially in open air) creating very little adhesion between its sliding contact surfaces [28, 29, 34]. Its super-hardness and rigidity also help in reducing friction. In the past, several researchers have proposed that gaseous species such as hydrogen, oxygen, or water molecules in the surrounding atmosphere can easily adsorb and effecttively passivate the dangling $\sigma$-bonds of diamond, thus leading to dramatically reduced adhesion and hence friction. More recent studies by Kumar et al. 
and Konicek et al. have demonstrated ultralow friction (i.e., down to 0.008) at the macroscale for ultra-nanocrystalline diamond (UNCD) $[30,31]$ when sliding in humid environment and under specific test conditions. Although exact mechanisms are unknown, such dramatic reductions in friction of diamond are attributed to surface adsorbates in test environments (and on sliding surfaces) since when diamonds are tested in inert or vacuum environments, their friction increases dramatically [28, 29, 32, 34].

Studies by Goto and Honda [36] have also demonstrated superlubric sliding behavior for sliding interfaces involving diamond sliding against $\mathrm{Ag}$ films on Si substrates. These researchers reported less than 0.01 friction coefficients in ultra-high vacuum when sliding diamond against Ag. Rubbing hydrogenterminated $\mathrm{Si}$ wafers against diamond was also shown to provide super-low friction (i.e., 0.003) as well in ultra-high vacuum [37]. Overall, super-hard and lowfriction nature of diamond makes it one of the most fascinating tribological materials for a wide range of applications but the cost and other limitations (i.e., high-temperature requirements for its thin film form and selectivity in substrate) impede the much broader uses of this material.

\section{Superlubricity in doped DLC films}

Besides the diamond and other carbon nanomaterials mentioned above, many types of DLC coatings have emerged over the years affording super-low friction and wear to sliding surfaces. In particular, with significant strides in PVD and CVD deposition technologies, DLC films with some alloying elements have become very popular among all carbon-based coatings [12]. Ease of deposition and cost-competitiveness, made them very practical for a wide range of demanding industrial applications often providing much improved physical, mechanical, and tribological properties. These films can be alloyed with a myriad of elements to achieve superior mechanical (toughness and hardness), thermal (high resistance to heat and thermal degradations), and tribological properties (better wettability and compatibility with liquid lubricants). In the following, we will summarize the recent progress toward achieving superlubricity in such coatings and compile them in Table 1.
Table 1 Summary of reported superlubricity studies on dopedDLCs.

\begin{tabular}{cccc}
\hline DLC type & Test environment & $\begin{array}{c}\text { Friction } \\
\text { coefficient }\end{array}$ & References \\
\hline N-doped & Nitrogen & 0.005 & {$[38,39]$} \\
Si-doped DLC & High vacuum & 0.007 & {$[40]$} \\
F-doped DLC & Ultra-high vacuum & 0.005 & {$[41]$} \\
S-doped DLC & Humid air & 0.004 & {$[42]$} \\
Fullerene-like & Air, 20 N load & 0.009 & {$[43]$} \\
DLC & & & \\
\hline
\end{tabular}

Carbon nitride films: The carbon nitride $\left(\mathrm{CN}_{x}\right)$ coatings represent a variant of hydrogen-free DLC in which a significant amount (i.e., 5-15 at.\%) of nitrogen is introduced into the amorphous network structure to enhance hardness, stiffness and tribological properties. Initially, nitrogen was added into DLC films to optimize surface chemical and tribological properties of magnetic hard-disks. They have been one of the most preferred hard-disk coatings for a quite long time. Many research papers were dedicated to $\mathrm{CN}_{x}$ 's tribological properties in the presence of a variety of molecularly thick oil films on top.

Concerted efforts by Kato and his co-workers have resulted in the synthesis of a superlow friction version of $\mathrm{CN}_{x}$ films $[38,39]$. Specifically, when tested in dry nitrogen (after a brief run-in or surface conditioning stage in oxygen), such films could provide friction coefficients of as low as 0.005. Superlubric behavior of $\mathrm{CN}_{x}$ is still a mystery, but theoretically, it has been proposed that such films can attain a very special surface termination state during the initial conditioning period and then assume a highly chemically inert and non-adhesive sliding behavior in nitrogen environments. Overall, the observed friction values of $0.005 \sim 0.01$ in nitrogen were attributed to the low-shear nature of tribologically generated products at the sliding interfaces and nitrogen gas atmosphere (since the superlubric regime was not sustainable in vacuum or other gases).

Silicon-doped DLCs: Silicon is widely used as a dopant in DLCs and credited for superior thermal stability and better tribological performance under lubricated conditions. Si incorporation was shown to be responsible for super-low friction coefficient (as low as 0.007 ) in high vacuum when rubbing against steel ball [40]. The Si-doped a-C:H films were synthesized in cyclotron resonance plasma made out of 
ethylene and silane gases. Super-low friction was attributed to the preferred orientation of transferred film along the sliding direction.

Fluorine-doped DLCs: Fluorine is another common dopant for DLC films. Compared to nitrogen, it is a bit more difficult to incorporate into DLC in large proportions (due to environmental sensitivity), but for a moderately F-doped hydrogenated DLC film, Fontaine et al. observed friction values down to 0.005 in ultra-high vacuum [41].

Sulfur-doped DLCs: In a study by Freyman et al., super-low friction of 0.004 was achieved with a sulfur-doped DLC under ambient air conditions. Sulfur incorporation was done by magnetron sputtering in a mixture of $\mathrm{Ar} / \mathrm{H}_{2} / \mathrm{H}_{2} \mathrm{~S}$ [42]. The super-low friction behavior of such films is thought to result from a weaker bonding between adsorbed water molecules (coming from the humid air) and the sulfur and hydrogen-rich surface.

Fullerene-like DLCs: Friction and wear performance of a hydrogenated fullerene-like DLC film sliding against $\mathrm{Si}_{3} \mathrm{~N}_{4}$ was shown to be very unique and depending on the contact load and the type of tribochemical films forming on rubbing surfaces, and friction coefficients of less than 0.01 could be achieved in open air. Mechanistically, such low friction was attributed to the formation of a hydrogen-rich transfer layer with low shear strength and highly elastic nature of the DLC film itself tolerating significant elastic deformation and hence the formation of larger contact area [43]. Table 1 summarizes the superlubric behavior of all DLC coatings discussed above.

\section{Bulk-, surface- and tribo-chemically enabled superlubricity in DLC coatings}

As mentioned in the introduction section, there exist many types of DLC films nowadays with a wide range of structural architectures and chemical compositions. Some are highly hydrogenated while others are hydrogen free or made of nano-layers or contain a variety of alloying elements. As a result, when subjected to tribological tests, they all exhibit very different friction and wear properties. Test conditions (load, speed, distance, etc.) in general, test environment and temperature in particular can have significant influence in their friction and wear behaviors. Many systematic studies directed toward the elucidation of effect of test environments (or conditions) on friction and wear of DLCs have led to the general conclusion that such variations in their tribological behaviors primarily result from a complex combination of intrinsic (or film-specific) and extrinsic (or test-condition-specific) factors $[3,44,45]$. While some DLCs are intrinsically lubricious in certain environments [14, 46-48], others need specific environmental species in order to provide low friction [10, 49-51].

Intrinsically, most DLCs are made of $\mathrm{sp}^{2}$ and $\mathrm{sp}^{3}$ bonded carbon atoms with or without hydrogen and other alloying elements incorporated into amorphous structure. Systematic studies have confirmed that the ratio of $\mathrm{sp}^{2} / \mathrm{sp}^{3}$, as well as the presence or absence of hydrogen or alloying elements in their microstructure can play important roles in their tribology [3]. For example, hydrogen-free DLCs perform quite well in humid and lubricated test environments (providing friction coefficients from 0.01 to 0.1 [10]); while under inert or vacuum test environments, their friction coefficients might go up as much as $1[12,52,53]$. These findings suggest that hydrogen-free DLC films are not intrinsically lubricious; rather, they rely on the chemical species of the test environments for low friction and wear. Conversely, hydrogenated or highlyhydrogenated DLC films provide some of the lowest friction and wear coefficients in clean, inert, and vacuum test environments [14, 44, 46, 52-54]; hence, these films can be categorized as intrinsically lubricious; in other words, they do not rely on external environmental species to provide low-friction.

Extrinsically, regardless of the type, almost all DLCs are subject to chemical, physical, and mechanical interactions with the species on their surroundings $[55,56]$. Figure 2 broadly summarizes the frictional behavior of hydrogenated and hydrogen-free DLC films with respect to relative humidity of test environment [56]. Besides the environment, test temperature can also have strong effect on their friction and wear behaviors [57]. If sliding against a different type of counterface material which resists transfer film formation, their frictional behaviors could also be very different. Overall, there exists no such DLC film that provides very low and consistent friction 


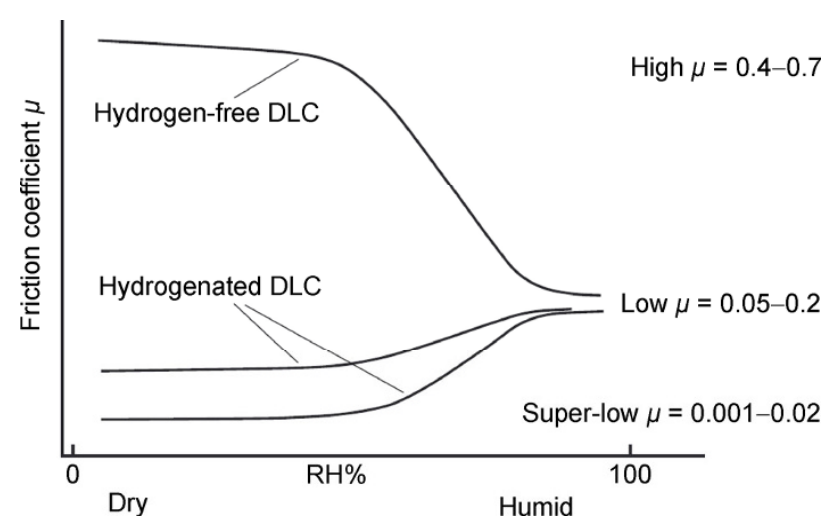

Fig. 2 General trend of friction coefficients of hydrogenated and hydrogen-free DLC films with respect to relative humidity of the test environment (Reproduced with permission from Ref. [56]).

and wear coefficients regardless of the test conditions or temperature. This is also true with other types of tribological coatings and materials.

Fundamentally, much of the friction in DLC films results from adhesive interactions at the sliding contact interfaces. In particular, covalent bonding resulting from unoccupied or dangling $\sigma$-bonds at the contact interface may account for the greatest portion of adhesive interactions and hence friction [14,44]. Capillary, van der Waals, and electrostatic attractions may also contribute to adhesion but at much lower scales. Covalent bonding is very strong and if present can cause very high friction between sliding diamond and DLC surfaces $[34,28,32]$. This is very typical of hydrogen-free tetragonal amorphous carbon (ta-C) or crystalline diamond films in which large amounts of $\mathrm{sp}^{3}$-bonded carbon atoms exist and when they are subjected to a sliding test in dry nitrogen or high vacuum, very high friction coefficients (i.e., as high as 1) may result $[34,52]$. Most of the other adhesive bonding possibilities mentioned above, i.e., van der Waals forces, electrostatic attraction, capillary forces, etc., are relatively weak under mild test conditions, or at nano-scales, these forces may also matter and can have significant effects on friction, but under macroscale or severe test conditions, their contributions to overall friction are much smaller.

Reactive gaseous species in test environments (such as water molecules, oxygen, hydrogen, alcohol and hydrocarbon gases) are known to interact with the sliding contact surfaces of all types of solid materials. Some of these may attach to tribological surfaces as a molecularly thick physisorbed layers, while others may chemically interact and form strongly bonded or chemisorbed films. Previous research has shown that such gas-surface interactions can have a beneficial or detrimental influence in the frictional behavior of DLC films [12]. For example, very high friction coefficients (i.e., 0.7-1) of hydrogen-free DLC films in vacuum and inert gases comes down to 0.05 to 0.2 levels when oxygen and/or water molecules are introduced into the test chambers [53-55]. Such a marked reduction in friction has been attributed to the existence of strong tribochemical interactions between such DLC surfaces and oxygen and water molecules in surrounding environments [55]. Specifically, TOFSIMS and X-ray photoelectron spectroscopy (XPS) analyses of sliding surfaces have shown that both oxygen and water had reacted with the carbon atoms at sliding interface and effectively passivated or terminated those $\sigma$-bonds which were responsible for strong adhesive interactions and hence high friction [58]. In the presence of hydrogen, nitrogen, or alloying elements in DLC, the nature of tribochemical interactions will be different. For example, Si and S-containing DLC films were reported to be far less sensitive to the presence or absence of water or oxygen molecules in the surrounding air [40, 42].

\subsection{Achieving superlubricity in DLC films by controlling bulk chemistry}

From the foregoing discussion, it is very clear that intrinsic and extrinsic factors can play a significant role in the tribological behaviors of all DLC films. To achieve superlubricity, these factors must be taken into account and optimized accordingly during deposition to meet the very specific chemical needs of the whole tribosystem including not only the DLC coating as a bulk but also the operating test environment, counterface material, surface finish, and other specific test conditions. In order to reduce or avoid strong covalent bond interactions ( $\sigma$-bonding in particular) at the sliding interface, the DLC films must be made highly chemically inert on their sliding surfaces (i.e., no free $\sigma$-bonds at sliding interface) or insensitive toward the counterface surfaces. Strong adhesive or chemical interactions will otherwise lead 
to high friction. A chemically inert DLC will help eliminate the extent of such interactions during sliding and thus provide super-low friction.

High chemical inertness of a DLC film can be achieved by controlling the chemical composition of gas discharge plasmas during the deposition process. Specifically, in plasma-enhanced CVD or PVD systems, one can modify the chemistry of plasma in such a way that the resultant DLC films will be highly inert or chemically very insensitive toward sliding counterfaces. For example, the synthesis of DLC films in gas discharge plasmas which contain large amounts of hydrogen will lead to fewer unoccupied $\sigma$-bonds left on the surface or in bulk and thus favor least amounts of adhesive interactions during sliding. This can be achieved by using hydrocarbon gases such as acetylene, methane, or ethylene as the source gas. The amount of hydrogen in these gasses may not be sufficient to result in a truly chemically inert DLC. In order to achieve much higher degree of hydrogenation and hence potentially superior chemical inertness, one can introduce excess hydrogen into the deposition chamber to increase hydrogen to carbon atom ratios to as high as 10 [14,59-62]. With excess hydrogen in plasma, growing DLC film tends to have large amounts of hydrogen in their structures (i.e., 30-40 at.\%). Due to constant hydrogen ion bombardment, carbon atoms bond to hydrogen to result in a highly hydrogenated random network structure. As a result, most of those dangling $\sigma$-bonds (which cause strong adhesive interaction and friction) are eliminated. Figure 3 shows the molecular structure of such a highly hydrogenate DLC.

Figure 4 compares the frictional performance of $\mathrm{C}_{2} \mathrm{H}_{2}(\mathrm{H} / \mathrm{C}$ ratio 1$)$ and $\mathrm{CH}_{4}(\mathrm{H} / \mathrm{C}$ ratio 4$)$ derived DLC with that of a highly hydrogen-containing DLC (which was synthesized in a gas discharge plasma consisting of $25 \% \mathrm{CH}_{4}+75 \% \mathrm{H}_{2}$ which would correspond to $\mathrm{H} / \mathrm{C}$ ratio of 10). As is clear, the film grown in $\mathrm{C}_{2} \mathrm{H}_{2}$ has a very unstable and high friction, whereas, the friction of film grown in $\mathrm{CH}_{4}$ is much steady and around 0.02 . However, the film grown in $25 \% \mathrm{CH}_{4}+75 \% \mathrm{H}_{2}$ gas discharge plasma provides a friction coefficient of about 0.003 . Atomic scale hydrogen concentrations of these three films would be the highest for the film grown in $25 \% \mathrm{CH}_{4}+75 \% \mathrm{H}_{2}$ gas discharge plasma

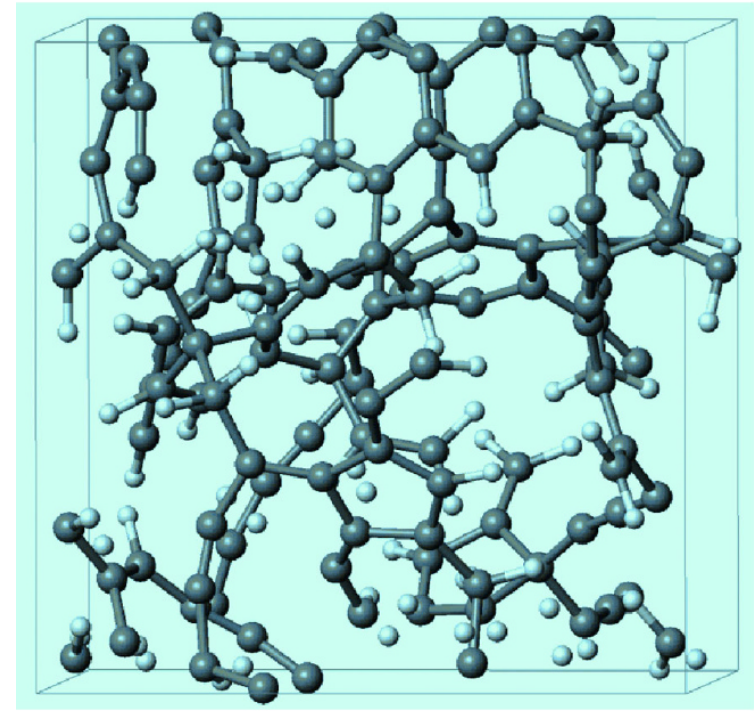

Fig. 3 Atomic scale simulation of a highly hydrogenated DLC film showing carbon-hydrogen random network structure with some free hydrogen occuping interstitial positions.

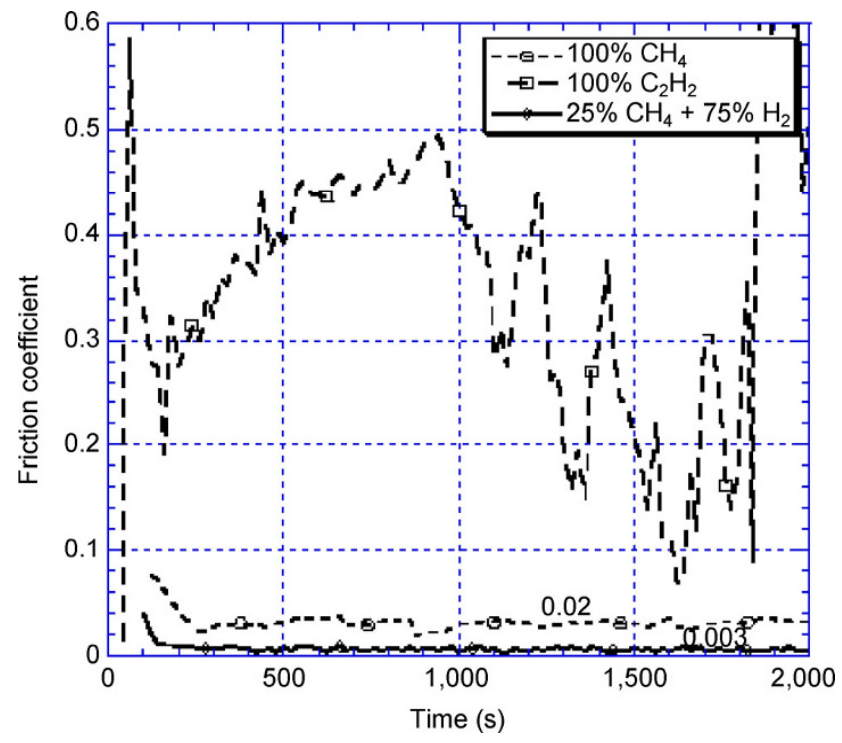

Fig. 4 Friction coefficients of DLC films derived from various source gases in a plasma enhanced CVD system (test conditions: load, $10 \mathrm{~N}$; speed, $0.5 \mathrm{~m} \cdot \mathrm{s}^{-1}$; temperature, $22-23^{\circ} \mathrm{C}$; test environment, dry $\mathrm{N}_{2}$ ) (Reproduced with permission from Ref. [48]).

and hence this film provides the lowest friction among all three DLCs that were tested. Specifically, if the bulk of DLC as illustrated in Fig. 3 contains large amounts of hydrogen, then the friction coefficient is extremely low as in Fig. 4. Conversely, if the bulk DLC film is poor in hydrogen, it cannot provide low friction, presumably due to some unoccupied $\sigma$-bond interactions triggering strong interfacial adhesion and 
hence high friction. Note that in Fig. 4, the difference between friction coefficient of a hydrogen poor-DLC film (grown in $\mathrm{H} / \mathrm{C}=1$ ) and a highly hydrogenated DLC film $(\mathrm{H} / \mathrm{C}=10)$ is more than 100 folds, underscoring the critically important role of bulk DLC chemistry on friction. When the same film was applied on a rigid sapphire ball and disk and then subjected to sliding test under conditions shown in Fig. 5, a friction coefficient of 0.001 could be achieved. Much lower friction in this case is attributed to the very rigid nature of sapphire ball and disk which would insure a much smaller Hertz contact spot and hence lesser amounts of adhesion and friction.

As discussed earlier, the incorporation of nitrogen, fluorine, sulfur, boron, or silicon into DLC films (alone or in addition to hydrogen) was also shown to reduce friction and wear of DLC films [38-42]. All and all, bulk chemical control or modification of DLC films can indeed lead to superlubric sliding behaviors as in Figs. 4 and 5.

One final note is that to achieve the lowest possible friction coefficients in the DLC films mentioned above, the surface roughness effects must also be considered and appropriate steps should be taken to avoid its deleterious effect. Due to their amorphous microstructures, most sputtered or PE-CVD DLC films have

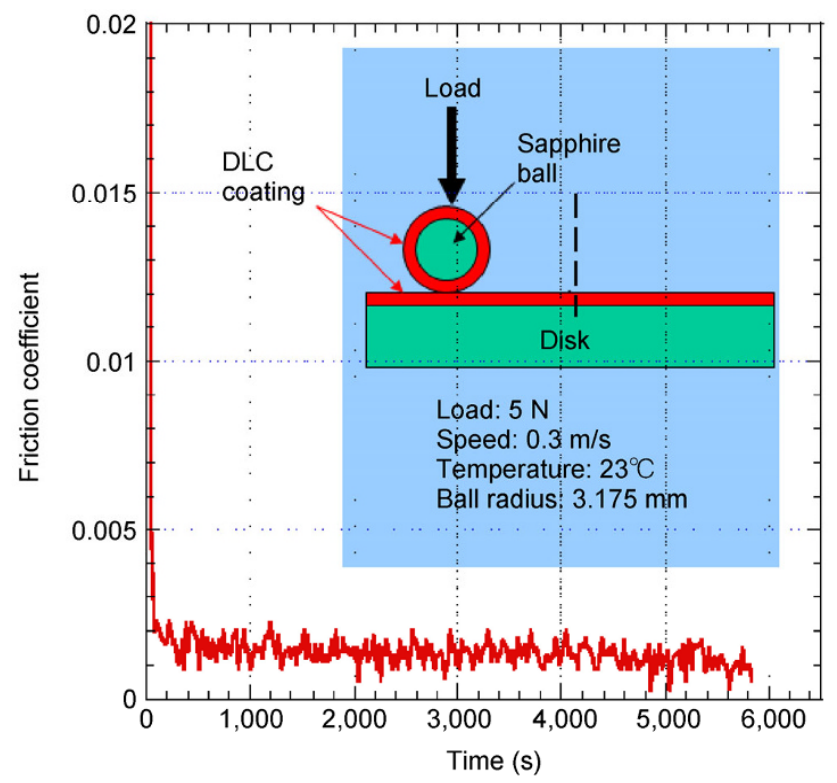

Fig. 5 Friction coefficient of a highly-hydrogenated DLC film (derived from $25 \% \mathrm{CH}_{4}+75 \% \mathrm{H}_{2}$ plasma; corresponding to $\mathrm{H} / \mathrm{C}$ ratio of 10) on sapphire substrate under test configuration and conditions shown. been very smooth (in fact down to a few nm thickness). Nanoscale roughness which is very typical of crystalline PVD nitride or carbide films does not apply to DLCs.

\subsection{Achieving superlubricity in DLC films by controlling near surface chemistry}

Hypothetically, if super-saturation or incorporation of hydrogen in the bulk of DLC leads to superlubricity (as discussed above), then the super-saturation of the top surface region of hydrogen free or poor DLC films with hydrogen should also lead to superlubricity. This was a major focus of our research effort on DLC films, since it would also help us further confirm the hydrogen lubrication mechanism of DLC that we had proposed [14, 44, 45, 47, 48]. The super-saturation of DLC surfaces with hydrogen can be done by treating such surfaces with a stream of hydrogen ions generated by an ion gun or it can also be done more conveniently in a PVD or plasma enhanced chemical vapor deposition (PECVD) deposition chamber using a hydrogen gas discharge plasma. Such a plasma can be generated by applying a bias voltage of about $-400 \mathrm{~V}$ to about $-600 \mathrm{~V}$ to the substrate holder. The gas pressure within the chamber may vary from about $20 \times 10^{-3}$ Torr to about $50 \times 10^{-3}$ Torr of hydrogen. DLC film to be plasma treated with hydrogen is normally attached to the negatively-biased substrate holder which gets bombarded by the positively charged hydrogen ions. In our studies, it was shown that only a few minutes of hydrogen plasma treatment are needed to form a hydrogen-rich top layer. Using such a method, we have shown that the plasma- modified hydrogen-free DLC and $\mathrm{CN}_{x}$ films exhibited remarkable reductions in their friction when compared to the same film prior to plasma-modification (i.e., reduction in friction is at least about $95 \%$ when compared to the film prior to modification) [45]. While the thickness depends on the gas pressure used in the plasma modification chamber and the length of time, however, a modified layer thickness can be in the range of from about $1 \mathrm{~nm}$ to $10 \mathrm{~nm}$. Figure 6 shows the effect of such hydrogen plasma treatment on a $\mathrm{CN}_{x}$ film. As is clear, prior to hydrogen plasma treatment, the friction coefficient of the film is around 0.18 , but after the treatment the friction coefficient comes down to 0.005 level. Such a dramatic reduction in friction also reflects on the 


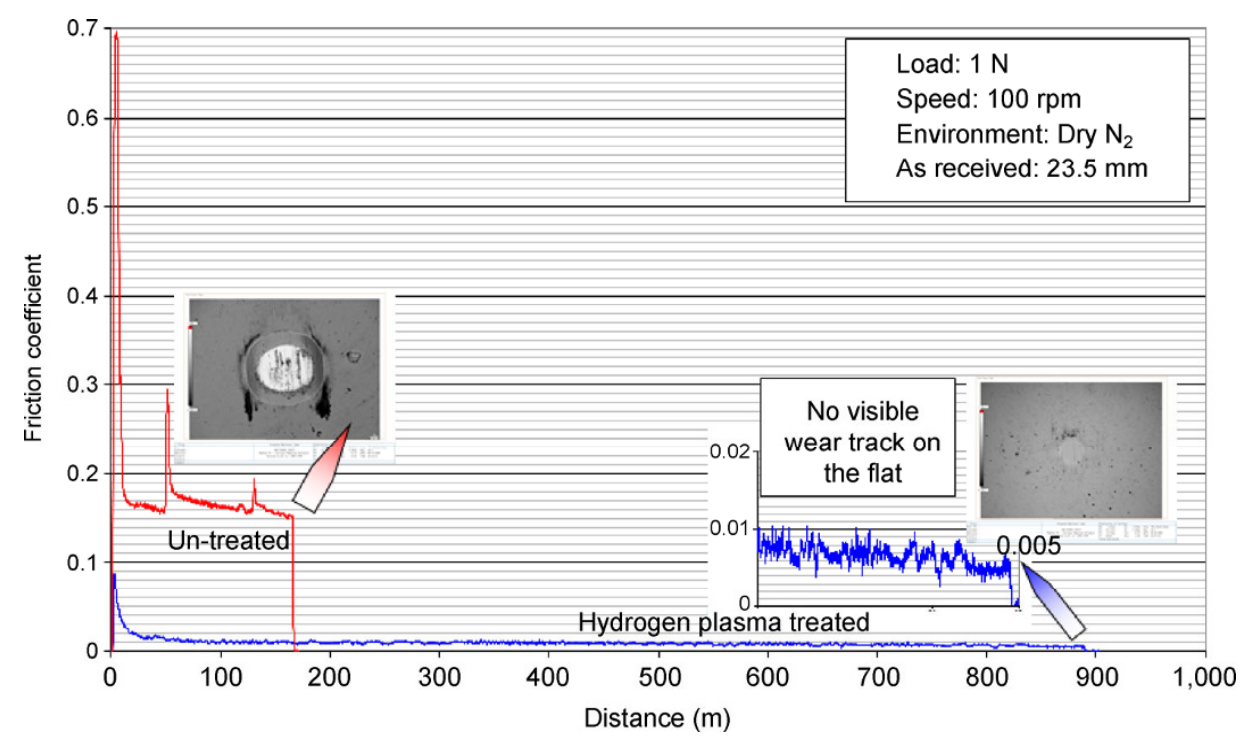

Fig. 6 The friction and wear performance of a $\mathrm{CN}_{x}$ film before and after hydrogen plasma treatment. At steady state, the friction coefficient of hydrogen-treated $\mathrm{CN}_{x}$ is around 0.005 (see detailed friction trace in inset). Also, the coating on ball side wears out without the hydrogen-treatment after about $160 \mathrm{~m}$ of sliding, while the wear of hydrogen-treated $\mathrm{CN}_{x}$ on steel ball is very insignificant and it has not worn out despite nearly $900 \mathrm{~m}$ of sliding distance.

wear of the rubbing surfaces. As shown in Fig. 6, the untreated $\mathrm{CN}_{x}$ wears out and the underlying substrate ball is clearly exposed. However, after the hydrogen plasma treatment, the wear is dramatically reduced as shown in the inset in Fig. 6.

Similar beneficial effects are also obtained after hydrogen plasma treatment of a hydrogen-free DLC film as reported in Ref. [45]. Specifically, without hydrogentreatment, the DLC film (about $200 \mathrm{~nm}$ thick) exhibited a friction coefficient of about 0.7 and could only last about $10 \mathrm{~m}$ before wearing off. However, after the hydrogen plasma treatment, the same film provided friction coefficients of 0.005 . Just like in the case of $\mathrm{CN}_{x}$, the wear was also reduced quite substantially.

TOF-SIMS imaging of the border between hydrogen treated and un-treated regions clearly showed higher contrast for hydrogen, confirming that the hydrogentreated part indeed became very rich in hydrogen and thus the superlow friction behavior of the hydrogen-free DLC after plasma treatment was primarily due to increased hydrogen concentration near the top surface as shown in Fig. 7.

\subsection{Achieving superlubricity in DLC Films by controlled tribochemistry}

If superlubricity is attainable through controlling bulk and near-surface chemistry, it should then be possible

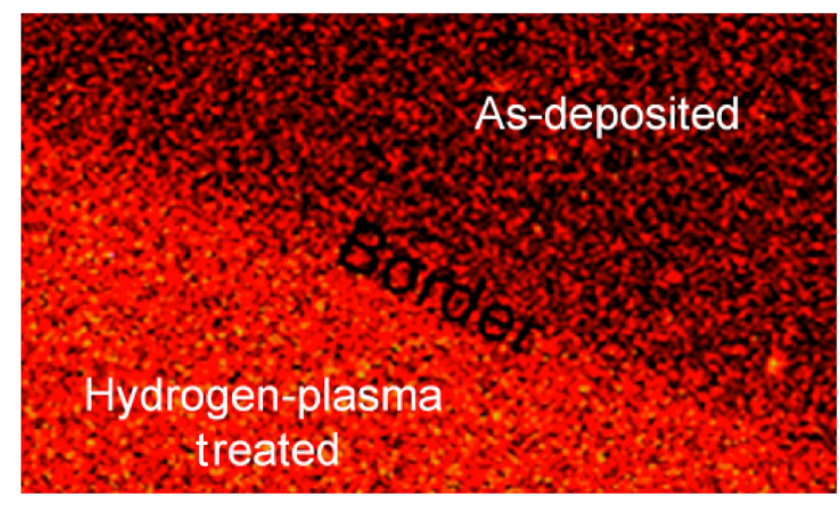

Fig. 7 Imaging hydrogen TOF-SIMS map of a region of hydrogen-free DLC film showing high hydrogen concentration for the hydrogen-plasma treated bottom part.

to modify only the sliding contact interfaces of DLC films through tribochemistry and thus achieve superlubricity in-situ during the dynamic sliding experiments. For example, such an experiment can be performed in a tightly sealed or enclosed test chamber filled with hydrogen. Due to highly flammable/explosive nature of hydrogen gas, strict measures and precautions must be taken during these tests (preferably, these tests should be run under partial pressures of hydrogen gas, like 10-100 torr or in mixture with some inert gases). As mentioned earlier, hydrogen-free DLC films provide very high friction in inert or vacuum test environments presumably because of the strong covalent bond (or $\sigma$-bond) interactions. To further 
substantiate this, we prepared a hydrogen-free DLC film on a steel substrate and subjected it to sliding tests in a high vacuum tribometer with a ball-on-disc contact geometry at room temperature and under 10 torr partial pressures of $\mathrm{Ar}$ and $\mathrm{H}_{2}$ gases. The contact loads used in these experiments were 1 and $2 \mathrm{~N}$ (peak Hertz pressures of $\approx 500$ to $600 \mathrm{MPa}$, respectively). The sliding velocity of the test pair was between $0.63-0.95 \mathrm{~cm} / \mathrm{s}$. To measure the true friction coefficient of the DLC film itself, we used coated balls sliding against the coated steel disks. After the tests, we used a TOF-SIMS instrument to generate chemical maps of the sliding contact surfaces of DLC films. The results of these tests are summarized in Table 2.

When the tests were run with hydrogen-free DLC under 10 torr partial pressure of Ar gas, the friction coefficient was rather unsteady and high (i.e., 0.6-0.7). Even after very short sliding distance, the wear of DLC on both the ball and disk sides were also very significant. However, when the same test is repeated on a new track and this time under 10 torr of hydrogen gas atmosphere, the friction coefficient of the sliding DLC pair was reduced to 0.03 level. When the same test is repeated in deuterium gas, the friction coefficient was even lower and in the orders of 0.01 to 0.02 levels (see Table 2). After the tests, the rubbing surfaces were examined with microscopy and mapped by a 3D non-contact profilometer. They

Table 2 Friction coefficients of hydrogen-free or -poor DLC coatings tested in hydrogen environment.

\begin{tabular}{|c|c|c|c|}
\hline Test pair & Test environment & $\begin{array}{l}\text { Friction } \\
\text { coefficient }\end{array}$ & $\begin{array}{c}\text { References } \\
\text { used }\end{array}$ \\
\hline $\begin{array}{c}\text { a-C coated } \\
\text { ball/a-C coated } \\
\text { disk }\end{array}$ & 10 torr $\mathrm{Ar}$ & 0.6 & $\begin{array}{c}\text { Authors' } \\
\text { experiment }\end{array}$ \\
\hline $\begin{array}{c}\text { a-C coated } \\
\text { ball/a-C coated } \\
\text { disk }\end{array}$ & 10 torr $\mathrm{H}_{2}$ & 0.03 & $\begin{array}{l}\text { Authors' } \\
\text { experiment }\end{array}$ \\
\hline $\begin{array}{c}\text { a-C coated } \\
\text { ball/a-C coated } \\
\text { disk }\end{array}$ & 10 torr $\mathrm{D}_{2}$ & 0.01 & $\begin{array}{l}\text { Authors' } \\
\text { experiment }\end{array}$ \\
\hline $\begin{array}{l}\text { a-C:H containing } \\
34 \text { at. } \% \text { hydrogen }\end{array}$ & 7.5 Torr $\mathrm{H}_{2}$ & 0.002 & {$[46]$} \\
\hline $\begin{array}{l}\mathrm{Al} \text { pin/a-C } \\
\text { coated disk }\end{array}$ & $\mathrm{N}_{2}$ & 0.7 & {$[50]$} \\
\hline $\begin{array}{l}\text { Al pin/a-C } \\
\text { coated disk }\end{array}$ & $\begin{array}{c}\mathrm{H}_{2}-\mathrm{He} \text { mixture } \\
\left(40 \text { vol. } \% \mathrm{H}_{2}-60\right. \\
\text { vol. } \% \mathrm{He})\end{array}$ & 0.015 & {$[50]$} \\
\hline
\end{tabular}

were also subjected to TOF-SIMS chemical imaging to check for any evidence of hydrogen or deuterium accumulation or tribochemical reaction within the wear track formed during tests. Indeed, there was significantly higher amount of hydrogen or deuterium within the wear track area as opposed to outside the wear track suggesting that there have been some tribochemical interactions between the hydrogen-free DLC surface and hydrogen and/or deuterium in surrounding environment. Clearly, the rubbing surfaces of DLC must have reacted tribochemically with the hydrogen and/or deuterium gas in the surrounding environment to form the highly hydrogen or deuterium rich wear tracks, and once formed, such a surface would certainly provide dramatic reductions in friction. So, in addition to bulk and surface chemical effects, tribochemical effects in the presence of hydrogen or deuterium gases can also lead to super-low friction and wear in DLC films.

In Table 2, results of friction tests in hydrogen from a few other researchers $[49,50]$ are also included. As is clear, they have also achieved dramatic reductions in friction when the tests were run in hydrogen environments. As discussed earlier, the extent of adhesive interactions and hence friction of sliding DLC surfaces are strongly affected by the presence or absence of covalent or $\sigma$-bond interactions. In vacuum or inert gas environments (like $\mathrm{Ar}, \mathrm{N}_{2}$, etc.), the friction is high mainly because of strong $\sigma$-bond interactions. Making and breaking of such bonds are thought to cause strong stick-slip and hence high and unsteady friction. When the tests are run in hydrogen or deuterium-containing environments, dangling $\sigma$-bonds created during rubbing action are effectively passivated and the stick-slip behavior is suppressed, and as a result, very smooth and superlow friction coefficients (as in Table 2) are attained in such gases.

During mechanical rubbing actions, there is no doubt that some of the bonded hydrogen and/or deuterium atoms may be removed and the dangling $\sigma$-bonds may have been re-exposed. Due to copious amount of hydrogen (or deuterium) in surrounding atmosphere, these bonds can be re-passivated instantly and the highly inert or hydrogen/deuterium terminated surface conditions are restored. Mainly because of this, the friction coefficient of DLC film remains very 
low and steady when rubbing in these gases. It is known that carbon bonds very strongly to hydrogen and has a high affinity to react with it when available. Due to such strong bonding, thermal desorption of hydrogen from a solid carbon material does not occur below $700{ }^{\circ} \mathrm{C}$ [62].

In short, the presence of hydrogen or deuterium gas in the vicinity of sliding DLC surfaces can trigger very unique tribochemistry which in turn overcomes strong covalent bond interactions at the sliding contact interfaces. Accordingly, hydrogen plays an important role in lowering adhesion and hence friction in hydrogen-free or poor DLC films. Model experiments summarized in Table 2 confirm this by revealing low friction for hydrogen and/or deuterium-rich surfaces as a result of favorable tribochemical interactions.

\section{Fundamental lubrication mechanisms}

Based on the friction test results from hydrogen-rich vs. hydrogen-free or -poor bulk DLC films or surfaces, the following mechanistic explanation can be proposed for the very critical role of hydrogen in the superlubric behavior of these films. As discussed above in detail, hydrogen bonds strongly to carbon and thus effectively passivates any free $\sigma$-bonds available within the bulk or on the surfaces [62]. Such a strong bonding and passivation of dangling $\sigma$-bonds can effectively reduce or even eliminate the extent of adhesive interactions across the sliding contact interface, thus resulting in super-low friction.

For bulk hydrogenation of DLC films, a highly hydrogenated gas discharge plasma can be generated during deposition process and thus the amount of hydrogen within the growing films as well as the hydrogen termination or coverage on their outer surfaces increases dramatically. Within the gas discharge plasmas, hydrogen molecules are reduced to hydrogen ions, and as these ionized hydrogen atoms reach the surface of growing DLC, they can easily react with carbon atoms to establish strong $\mathrm{C}-\mathrm{H}$ bonding. Some hydrogen may remain as un-bonded interstitials, as was shown in Fig. 3. As a result, high hydrogen content within the DLC structure as well on its surface should effectively eliminate the possibility of any unoccupied $\sigma$-bonds remaining and potentially participating in adhesive interactions during sliding. Excess or free hydrogen within the films can always diffuse to sliding surfaces and hence replenish or replace those hydrogen atoms that may have been removed due to frictional heating and/or mechanical wear during sliding contact.

For top surface hydrogenation, hydrogen-free or -poor DLC films can be subjected to ionized hydrogen bombardment or treatment in a discharge plasma. As a result, their top surfaces become very rich in hydrogen and this leads to the same effect as in bulk hydrogenation and thus provides super-low friction when sliding.

For the tribochemically assisted hydrogenation of hydrogen-free or -poor DLCs, fresh dangling $\sigma$-bonds generated during sliding can react with hydrogen or deuterium in the surrounding environment thus generating a hydrogen-rich top surface layer as in the previous two cases and thereby providing super-low friction. Overall, regardless of the methods used, as long as the sliding DLC surfaces are sufficiently hydrogenated, they can provide super-low friction and wear. Figure 8 below is an atomic scale illustration of the highly hydrogenated DLC surfaces providing super-low friction and wear. Once the free electrons of those hydrogen atoms on the surface are paired with the dangling $\sigma$-bonds of surface carbon atoms, the electrical charge density of hydrogen atoms is concentrated toward the other side of the hydrogen nucleus and hence away from the surface. This is expected to result in positively charged hydrogen protons being closer to the surface than the paired electron, which is tied to the dangling $\sigma$-bond of the

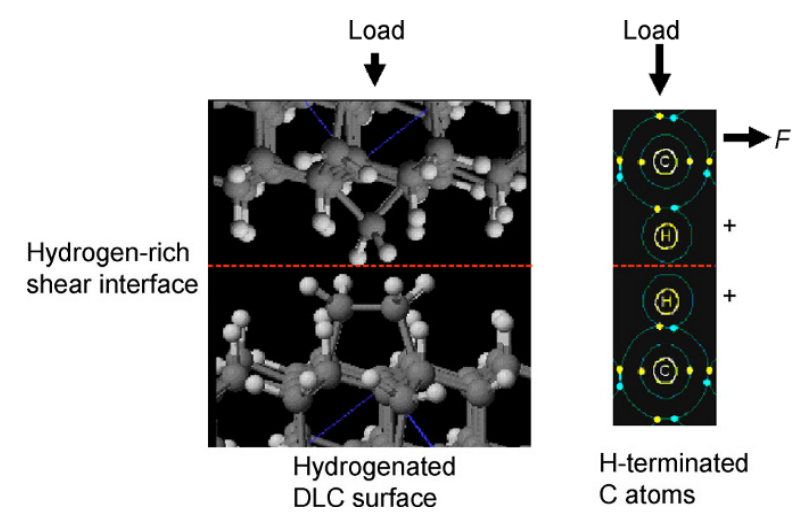

Fig. 8 A mechanistic model for the super-low friction behavior of highly hydrogenated DLC surfaces (adopted from Ref. [44]). 
surface carbon atoms. Therefore, the creation of such a dipole configuration at the contact spots should generate repulsive rather than attractive forces between the hydrogen-terminated sliding surfaces of the DLC films [44]. In support of the proposed mechanism described above, several researchers have simulated much lower friction for $\mathrm{H}$-terminated diamond and DLC surfaces using MD, ab-intio, and DFT calculations [63-68].

\section{Summary and future direction}

DLC films have emerged over the years as scientifically very intriguing and practically very valuable tribological materials for numerous industrial applications. The unmatched flexibility in producing them in a wide range of chemistries and structures as well as ease of deposition made them very versatile and costeffective for mass-production. They can be doped or alloyed with all kinds of other elements to increase their functionality even further. Structurally, they are mostly amorphous but can also be prepared as nanocomposite and -layered coatings. When synthesized in hydrogen-containing environments, they may contain large amounts of hydrogen in their structures and offer superlubricity under dry and inert tribological conditions. Depending on the nature and extent of bulk, surface, and tribochemistry, they can provide super-low friction coefficients down to 0.001 level. High hydrogen concentration within their bulks, on their surfaces or at their sliding contact interfaces can lead to superlubricity.

Despite the very intriguing and multifaceted nature of friction, we have come a long way in controlling its adverse impacts on mechanical systems in so many ways. Dedicated research during the last three decades has particularly been very influential in bringing friction down to some extremely low values. As the energy and environmental sustainability for our continued mobility and quality of life is in question, we must work harder to reduce energy intensity and carbon footprint of future mechanical systems by further reducing or even eliminating friction between contacting surfaces that are in relative motion. This will undoubtedly help maintain a livable environment and save some energy for generations to come.

\section{Acknowledgments}

This work is supported by the U.S. Department of Energy, Office of Energy Efficiency and Renewable Energy, under Contract No. DE-AC02-06CH11357. The authors thank their colleagues and collaborators who participated in the preparation, testing, and characterization of the DLC coatings discussed in this paper.

Open Access: This article is distributed under the terms of the Creative Commons Attribution License which permits any use, distribution, and reproduction in any medium, provided the original author(s) and source are credited.

\section{References}

[1] Erdemir A, Martin J-M. Superlubricity. New York (USA): Elsevier, 2007

[2] Holmberg K, Andersson P, Erdemir A. Global energy consumption due to friction in passenger cars. Tribol Int 47: 221-234 (2012).

[3] Erdemir A, Donnet C. Tribology of diamond like carbon films: Current status and future prospects (topical review). $J$ Phys D: Appl Phy 39: R311-327 (2006)

[4] Holmberg K, Matthews A. Coatings Tribology-Properties, Mechanisms, Techniques and Applications in Surface Engineering. Amsterdam (The Netherlands): Elsevier, 2009.

[5] Erdemir A. Engineered tribological interfaces for improved boundary lubrication. Tribol Int 38:249-256 (2005).

[6] Schmellenmeier H. Die Beeinflussung von festen Oberflachen durch eine ionisierte. Experimentelle Technik der Physik 1: 49-68 (1953)

[7] Donnet C, Erdemir, A. Tribology of Diamondlike Carbon Films: Fundamentals and Applications. New York (USA): Springer, 2008.

[8] Casiraghi C, Robertson, J, Ferrari A C. Diamondlike carbon for data and beer storage. MaterToday 10:44-53 (2007)

[9] Kano M. DLC coating technology applied to sliding parts of automotive engine. New Diamond and Frontier Carbon Technol 16:201-210 (2006)

[10] Kano M. Super low friction of DLC applied to engine cam follower lubricated with ester-containing oil. Tribol Int 39: 1682-1685 (2006)

[11] Gåhlin R, Larsson M, Hedenqvist P. ME-C:H coatings in motor vehicles. Wear 249:302-309 (2001)

[12] Sanchez-Lopez J C, Fernandez A, Donnet C. Doping and 
alloying effects on DLC coatings. In Tribology of Diamondlike Carbon Films: Fundamentals and Applications. New York: Springer, 2008: 311-338.

[13] Robertson J. Diamond-like amorphous carbon. Mater Sci Eng R: Rep 37: 129-281 (2002)

[14] Erdemir A, Eryilmaz O L, Fenske G. Synthesis of diamondlike carbon films with superlow friction and wear properties. $J$ Vac Sci Technol A 18: 1987-1992 (2000)

[15] Matsumoto N, Mistry K, Kim J-H, Eryilmaz O L, Erdemir A, Kinoshita H, Ohmae N. Friction-reducing properties of onion-like carbon under high contact pressure in liquid lubricant. Tribology-Materials, Surfaces, and Interfaces 6: 116-120 (2012)

[16] Joly-Pottuz L, Matsumoto N, Kinoshita H, Vacher B, Belin M, Montagnac G, Martin J M, Ohmae N. Diamond-derived carbon onions as lubricant additives. Tribol Int 41: 69-78 (2008)

[17] Mate C M, McClelland G M, Erlandsson R, Chiang S. Atomic-scale friction of a tungsten tip on a graphite surface. PRL 59: 1942-1945 (1987)

[18] Hirano M. Superlubricity: A state of vanishing friction. Wear 254(10): 932-940 (2003).

[19] Dienwiebel M, Verhoeven G S, Pradeep N, Frenken J W M, Heimberg J A., Zandbergen H W. Superlubricity of graphite. PRL 92:126101-126105 (2004)

[20] Miura K, Tsuda D, Sasaki N. Superlubricity of C60 Intercalated Graphite Films. J Surf Sci Nanotechnol 3: 21-23 (2005)

[21] Liu Z, Yang J R, Grey F, Liu J Z, Liu Y L, Wang Y B, Yang Y L, Cheng Y, Zheng Q S. Observation of microscale superlubricity in graphite. Phys Rev Lett 108: 205503 (2012)

[22] Berman D, Erdemir A, Sumant AV. Few layer graphene to reduce wear and friction on sliding steel surfaces. Carbon 54: 454-459 (2013)

[23] Berman D, Erdemir A, Sumant A V. Reduced wear and friction enabled by graphene layers on sliding steel surfaces in dry nitrogen. Carbon 59: 167-175 (2013)

[24] Xu L, Ma T B, Hu Y Z, Wang H. Vanishing stick-slip friction in few-layer graphenes: The thickness effect. Nanotechnology 22: 285708 (2011)

[25] Feng X, Kwon S, Park J Y, Salmeron S. Superlubric sliding of graphene on nanoflakes of graphene. ACS Nano 7: 17181724 (2013)

[26] Zhang R, Ning Z, Zhang Y, Zheng Q, Chen Q, Xie H, Zhang Q, Qian W, Wei F. Superlubricity in centimetres-long double-walled carbon nanotubes under ambient conditions. Nat Nanotechnol 8: 912-916 (2013)
[27] Erdemir A, Fenske G R, Bindal C. Friction and wear properties of smooth diamond films grown in fullerene-argon plasmas. Diam Relat Mater 5: 923-931 (1996)

[28] Gardos M N, Soriano B L. The effect of environment on the tribological properties of polycrystalline diamond films. $J$ Mater Res 5: 2599-2609 (1990)

[29] Bowden F P, Bowden F R S, Young J E. Friction of diamond, graphite, and carbon and the influence of surface films. Proc Roy Soc 208: 444-455 (1951)

[30] Kumar N, Sharma N, Dash S, Popov C, Kulisch W, Reithmaier J P, Favaro G, Tyagi A K, Raj B. Tribological properties of ultrananocrystalline diamond films in various test atmosphere, Tribol Int 44: 2042-2049 (2011)

[31] Konicek A R, Grierson D S, Gilbert P U P A, Sawyer W G, Sumant A V, Carpick R W. Origin of ultralow friction and wear in ultrananocrystalline diamond. Phys Rev Lett 100: 235502 (2008)

[32] Miyoshi K, Wu R L C, Arscadden A, Barnes N, Jackson L J. Friction and wear of plasma-deposited diamond films. Appl Phys 74: 4446-4454 (1993)

[33] Gruen D M. Nanocrystalline diamond films. Annu Rev Mater Sci 29: 211-259 (1999)

[34] Erdemir A, Fenske G R, Krauss A R, Gruen D M, McCauley T, Csencsits R T. Tribological properties of nanocrystalline diamond films. Surf Coat Technol 121: 565-572 (1999)

[35] Krauss A, Auciello O, Gruen D, Jayatissa A, Sumant A, Tucek J, Macini D, Molodvan M, Erdemir A, Ersoy D, et al. Ultrananocrystalline diamond thin films for MEMS and moving mechanical assembly devices. Diam Relat Mater 10: 1952-1961 (2001)

[36] Goto M, Watanabe K, Honda F. Superlubricity of diamond sliding on the Ag monolayer/Si(111) and the effect of gas adsorption. Surf Sci 507-510: 922-927 (2002)

[37] Masuda H, Honda F. Low friction of a diamond/H-terminated Si(111) sliding system. IEEE Trans Magnetics 39: 903908(2003)

[38] Kato K, Umehara N, Adachi K. Friction, wear and $\mathrm{N}_{2^{-}}$ lubrication of carbon nitride coatings: A review. Wear 254:1062-1069 (2003)

[39] Kato K, Adachi K. Superlubricity of $\mathrm{CN}_{x}$-coatings in nitrogen gas atmosphere. In Tribology of Diamondlike Carbon Films: Fundamentals and Applications. New York: Springer, 2008: $342-364$.

[40] Sugimoto I, Miyake S. Oriented hydrocarbons transferred from a high performance lubricative amorphous $\mathrm{C}: \mathrm{H}: \mathrm{Si}$ film during sliding in a vacuum. Appl Phys Lett 56: 1868-1870 (1990)

[41] Fontaine J, Loubet J L, Le Mogne T, Grill A. Superlow 
friction of diamond-like carbon films: A relation to viscoplastic properties. Tribol Lett 17(4): 709-714 (2004)

[42] Freyman C A, Chen Y, Chung Y W. Synthesis of carbon films with ultra-low friction in dry and humid air. Surf Coat Technol 201: 164-167 (2006)

[43] Wang Z, Wang C B, Zhang B, Zhang J Y. Ultralow friction behaviors of hydrogenated fullerene-like carbon films: Effect of normal load and surface tribochemistry. Tribol Lett 41: 607-615 (2011)

[44] Erdemir A. The role of hydrogen in tribological properties of diamondlike carbon films. Surf Coat Technol 146-147: 292-297(2001)

[45] Eryilmaz O L, Erdemir A. On the hydrogen lubrication mechanism(s) of DLC films: An imaging TOF-SIMS study. Surf Coat Technol 203: 750-755 (2008)

[46] Fontaine J, Le Mogne T, Loubet J L, Belin M. Achieving superlow friction with hydrogenated amorphous carbon: Some key requirements. Thin Solid Films 482: 99-108 (2005)

[47] Erdemir A. Genesis of superlow friction and wear in diamondlike carbon films. Tribol Int 37: 1005-1012 (2004)

[48] Erdemir A. Design criteria for super lubricity in carbon films and related microstructures. Tribol Int 37: 577-583 (2004)

[49] Fontaine J, Belin M, Le Mogne T, Grill A. How to restore superlow friction of DLC: The healing effect of hydrogen gas. Tribol Int 37: 869-877 (2004)

[50] Konca E, Cheng Y-T, Weiner A M, Dasch J M, Alpas A T. The role of hydrogen atmosphere on the tribological behavior of non-hydrogenated DLC coatings against aluminum. Tribol T 50: 178-186 (2007)

[51] Matta C, Eryilmaz O, De Barros Bouchet M I, Erdemir A, Martin J M, Nakayama K. On the possible role of triboplasma in friction and wear of diamondlike carbon films in hydrogen-containing environments. $J$ Phys: $D$ 42: 075307 (2009)

[52] Kim H I, Lince J R, Eryilmaz O L, Erdemir A. Environmental effects on the friction of hydrogenated DLC films. Tribol Lett 21: 53-58 (2006)

[53] Andersson J, Erck R A, Erdemir A. Frictional behavior of diamondlike carbon films in vacuum and under varying water vapor pressure. Surf Coat Technol 163-164: 535-540 (2003)

[54] Andersson J, Erck R A, Erdemir A. Friction of diamondlike carbon films in different atmospheres. Wear 254: 1070-1075 (2003)

[55] Sanchez-Lopez J C, Erdemir A, Donnet C, Rojas T C. Friction-induced structural transformations of DLC coatings under different atmospheres. Surf Coat Technol 163-164:
444-450 (2003)

[56] Ronkainen H, Holmberg K. Environmental and thermal effects on the tribological performance of DLC coatings. In Tribology of Diamond-Like Carbon Films. New York (USA): Springer, 2008: 155-200.

[57] Erdemir A, Fenske G R. Tribological performance of diamond and diamondlike carbon films at elevated temperatures. Tribol T 39: 787-794 (1996)

[58] Eryilmaz O L, Erdemir A. TOF-SIMS and XPS characterization of diamondlike carbon films after tests in inert and oxidizing environments. Wear 265: 244-254 (2008)

[59] Eryilmaz O L, Erdemir A. Surface analytical investigation of nearly frictionless carbon films after tests in dry and humid nitrogen. Surf Coat Technol 201: 7401-7407 (2007)

[60] Erdemir A, Eryilmaz O L, Nilufer I B, Fenske G R. Effect of source gas chemistry on tribological performance of diamond-like carbon films. Diam Relat Mater 9: 632-637 (2000)

[61] Erdemir A, Eryilmaz O L, Nilufer I B, Fenske G R. Synthesis of superlow friction carbon films from highly hydrogenated methane plasmas. Surf Coat Technol 133-134: 448-454 (2000)

[62] Su C, Lin J C. Thermal desorption of hydrogen from the diamond (100) surface. Surf Scie 406: 149-166 (1998)

[63] Gao G T, Mikulski P T, Harrison J A. Molecular-scale tribology of amorphous carbon coatings: Effects of film thickness, adhesion, and long-range interactions. JACS 124(24): 7202-7209 (2002)

[64] Dag S, Ciraci S. Atomic scale study of superlow friction between hydrogenated diamond surfaces. Phys Rev $B$ 70: 241401 (2004)

[65] Guo H, Qi Y, Li X. Predicting the hydrogen pressure to achieve ultralow friction at diamond and diamondlike carbon surfaces from first principles. Appl Physs Lett 92(24): 241921 (2008)

[66] Morita Y, Shibata T, Onodera T, Sahnoun R, Koyama M, Tsuboi H, Miyamoto A. Effect of surface termination on superlow friction of diamond film: A theoretical study. Jpn J Appl Phys 47(4S): 3032 (2008)

[67] Hayashi K, Tezuka K, Ozawa N, Shimazaki T, Adachi K, Kubo M. Tribochemical reaction dynamics simulation of hydrogen on a diamond-like carbon surface based on tightbinding quantum chemical molecular dynamics. J Phys Chem C 115(46): 22981-22986 (2011)

[68] Zilibotti G, Righi M C. Ab-initio calculation of the adhesion and ideal shear strength of planar diamond interfaces with different atomic structure and hydrogen coverage. Langmuir 27(11): 6862-6867 (2011) 


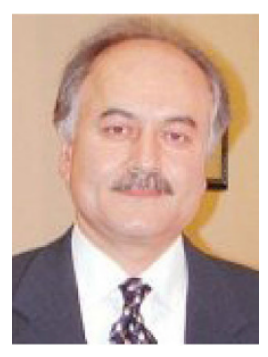

Ali ERDEMIR. He is a Distinguished Fellow and a Senior Scientist at Argonne National Laboratory with broad experience and expertise in the fields of materials science, surface engineering, and tribology. $\mathrm{He}$ received his MS and $\mathrm{PhD}$ degrees in Materials Science and Engineering from the Georgia Institute of Technology in 1982 and 1986, respectively and his BS from Istanbul Technical University in 1977. In recognition of his pioneering research, Dr. Erdemir has received numerous awards and honors, including the University of Chicago's Medal of Distinguished Performance, five R\&D-100
Awards, two Al Sonntag and an Edmond E. Bisson Awards from the Society of Tribologists and Lubrication Engineers, and an Innovative Research Award from the Tribology Division of ASME. He is a Fellow of ASME, STLE, AVS, and ASM-International. He authored/co-authored more than 280 research articles (190 of which are refereed), 18 book/handbook chapters, edited two books, presented more than 150 invited/keynote/lenary talks, and holds 15 U.S. Patents. His current research is directed toward nanoscale design and large-scale manufacturing of new materials, coatings, and lubricants for a broad range of applications in manufacturing, transportation and other energy conversion and utilization systems. 